\title{
Pharmaceutical counseling: Between evidence-based medicine and profits
}

\author{
S.N. Egorova* and T. Akhmetova \\ Kazan State Medical University, Department of Pharmacy, Kazan, Russia \\ *Corresponding author. E-mail: zimsve@yandex.ru
}

BACKGROUND: The number of pharmacies, which produce drug formulations locally, has recently considerably reduced in Russia. Pharmacies mainly operate as retailers of industrially manufactured drugs.

Pharmaceutical consultation of customers at pharmacies aimed at responsible self-medication is the most popular and accessible feature of pharmaceutical care. In Russia there is a significant list of medicines approved for sale in pharmacies on a non-prescription basis that is specified in the product label. In this regard, the role of pharmacists in public health in Russia increases. Pharmacist, working directly with population, is an important figure for the rational use of medicines. This type of work requires high level of professional training and appropriate ethics.

OBJECTIVES: To explore the current status of pharmaceutical counseling in Russia.

METHODS: Situation analysis, surveys of pharmacists.

RESULTS: Our experience in the system of postgraduate professional education, the results of the survey of pharmacists, and the long-term dialogue with pharmacists allowed us to identify several unresolved issues in the work of a pharmacist selling non-prescription drugs.

Lack of differentiation in the functions of a pharmacist with a higher education and pharmaceutical technologist: In production/industrial pharmacy technicians are engaged in manufacturing of pharmaceutical formulations. However, due to the loss of production functions technologists had to move away from production laboratories of apothecaries to the sales area. Currently, the apothecary's assignment to receive prescriptions and dispense medications can be fulfilled by either a pharmacist or a pharmaceutical technician. It significantly discerns the pharmacy from the medical organization with clearly delineated functions of doctors and nurses. Russian regulations should consider the level of education required for high-quality pharmaceutical counseling.

Contradiction between the pharmacist's special functions and trade procedure with the lack of pharmaceutical counseling standards: Article 1.1 "Code of Ethics of the pharmaceutical worker of Russia" states: "The main task of the professional activity of the pharmaceutical worker - protection of human health", Article 1.3 states that a pharmaceutical worker must take professional decisions solely in the interests of a patient [1]. However, the pharmacy is a trade organization, thus as a retailer the pharmacy is directly interested in making profits and increasing sales of pharmaceutical products, including non-prescription medicines. Moreover, while the clinical medicine is monitored for unjustified prescribing and measures are being taken to prevent polypharmacy, for a pharmacist the growing sales of over-the-counter drugs, active promotion of dietary supplements, homeopathic medicines, medical devices, and, consequently, an increase of financial indicators (particularly "average purchase size") all are characteristics of success [2]. 
Rational use of over-the-counter medicines requires introduction of pharmaceutical counseling standards (pharmaceutical care) according to symptoms - major reasons to visit a pharmacy as part of responsible self-medication (cold, sore throat, headache, diarrhea, etc.). Standards of pharmaceutical counseling should be objective, reliable and up-to-date and contain recommendations for the rational use of over-the-counter drugs as well as indications requiring treatment to the doctor. Standardization of pharmaceutical counseling in terms of Evidence-based Pharmacy would enhance the efficiency, safety and cost-effectiveness of over-the-counter medicines.

Currently, the lack of clinical component in the higher pharmaceutical education and the lack of approved standards of pharmaceutical counseling lead to the introduction of cross-selling technologies (which are broadly applied in other areas of trade, for example, the offer of a boot-polish during the sale of shoes) to the pharmaceutical practice [2,3]. However, drugs belong to a special group of products, proper selection of which requires special education, and the consumer is not always able to evaluate the quality of the recommendations. Marketing cross-selling recommendations are aimed at promotion of the over-the-counter medicines for customers buying prescription drugs. For example, business coaches recommend the pharmacists to make additional offers: with the purchase of physician-prescribed antibiotics - offer of vitamins, with prescribed nonsteroidal anti-inflammatory drugs - commercially available ointment with non-steroidal topical formulation ("to enhance the effect") and others. These recommendations do not agree with evidence-based medicine and lead to inefficient use of over-thecounter drugs and unjustified financial expenses.

CONCLUSIONS: Thus, to ensure the rational use of medicines permitted for free (non-prescription) dispensing at the pharmacies, pharmaceutical information needs standardization on the basis of evidencebased medicine as well as standardization of the pharmaceutical counseling service. The development of practical recommendations on the rational use of over-the counter medicines by doctors and pharmacists with further adoption at the state level, the recommendation of most secure, efficient and cost-effective over-the-counter medications during pharmaceutical counseling in pharmacies will contribute to the restoration and preservation of public health.

Keywords: Pharmaceutical counseling, evidence-based medicine, profits, pharmacy, pharmacist

Conflict of interest statement: None.

\section{References}

[1] Ethical code of pharmaceutical worker in Russia (pharmacists and druggists). Novaya Apteka. Apteka i rynok. 1999;8: p. 17-21. Russian

[2] Tchertkov J. "Pyramid of apothecary's sales" - proven tool to increase average purchase size. [Internet]. 2012 Feb 13 [cited 2012 Feb 13]; Available from: http://www.apteka.ua/article/124706 . Russian

[3] Lisovsky P. Sales management in the apothecary of high-profit goods. [Internet]. 2012 May 15 [cited 2012 May 15]; Available from: http://www.pharmvestnik.ru/publs/lenta/obzory/organizatsija-prodazhi-v-apteke-vysokopribyljnyxtovarov.html\#.UClW3qBadiA. Russian 